\title{
Mudanças nos papéis ocupacionais de mães, pais e cuidadores após o nascimento de uma criança com deficiência
}

\author{
Cambios en los roles ocupacionales de madres, padres y cuidadores \\ después del nacimiento de un niño o niña con discapacidad
}

Changes in the occupational roles of parents and caregivers after the birth of a child with a disability

\author{
Dyuly de Freitas Pereira ${ }^{1}$ \\ Daniela Tonús ${ }^{2}$
}

Recibido: 25 de junio 2021 • Enviado para modificación: 31 de agosto 2021 • Aceptado: 1 de diciembre 2021

De Freitas Pereira, D. y Tonús, D. (2022). Mudanças nos papéis ocupacionais de mães, pais e cuidadores após o nascimento de uma criança com deficiência. Revista Ocupación Humana, 22(1), 12-27. https://doi. org/10.25214/25907816.1145

\section{RESUMO}

O nascimento de uma criança com deficiência transforma o cotidiano de uma família, alterando os papéis ocupacionais desempenhados. O objetivo do estudo foi identificar alterações nos papéis ocupacionais de mães, pais e cuidadores após o nascimento de uma criança com deficiência. Foi uma abordagem quantitativa e qualitativa. A coleta de dados foi realizada por meio da Lista de Identificação dos Papéis Ocupacionais e de uma entrevista semiestruturada. Os resultados foram analisados com estatística descritiva e análise de conteúdo. Participaram do estudo dez mães, pais e cuidadores de alunos de uma Escola e Associação de Pais e Amigos dos Excepcionais da região central do estado do Rio Grande do Sul - Brasil. Foi possível constatar que pode haver influência no desempenho dos papéis ocupacionais a partir do nascimento de uma criança com deficiência, destacando uma perda de $70 \%$ e $60 \%$, respectivamente, nos papéis de estudante e trabalhador, bem como a aquisição de um novo papel, o de cuidador. As famílias estabeleceram, no decorrer do tempo, estratégias para adaptação e reestruturação na dinâmica familiar. O resgate de papéis ocupacionais ou aquisição de novos papéis é um importante caminho para intervenções junto a essa população.

\footnotetext{
${ }^{1}$ Terapeuta ocupacional. Estudiante de posgrado en Desorden del Espectro Autista, Child Behavior Institute of Miami. Santa Maria, Brasil. dyuly.freitas@gmail.com iD https://orcid.org/0000-0001-9303-6149

${ }^{2}$ Terapeuta ocupacional. Especialista en Salud Colectiva. Magíster en Rehabilitación e Inclusión. Doctora en Educación. Docente, Universidade Federal de Santa Maria. Santa Maria, Brasil. dtonus@hotmail.com (iD https://orcid.org/0000-0001-9924-2891
} 


\title{
PALAVRAS-CHAVE
}

acontecimentos que mudam a vida, parentalidade, cuidadores, crianças com deficiência, Terapia Ocupacional

\section{RESUMEN}

El nacimiento de un hijo o hija con discapacidad transforma la vida diaria de una familia, cambiando los roles ocupacionales que las personas desempeñan. El objetivo del estudio fue identificar cambios en los roles ocupacionales de madres, padres y cuidadores, después del nacimiento de un niño o niña con discapacidad. El enfoque fue cuantitativo y cualitativo. La recolección de datos se realizó mediante la Lista de Identificación de Roles Ocupacionales y una entrevista semiestructurada. Para el análisis se utilizaron estadística descriptiva y análisis de contenido. Participaron diez madres, padres y cuidadores de estudiantes de una Escuela y Asociación de Padres y Amigos de los Excepcionales de la región central del estado de Rio Grande do Sul, Brasil. El nacimiento de un niño o niña con discapacidad puede influir en el desempeño de roles ocupacionales. Se destaca una disminución del $70 \%$ y $60 \%$, respectivamente, en los roles de estudiante y trabajador/a, considerados por la totalidad de participantes como muy importantes en su vida diaria. A lo largo del tiempo, las familias han establecido estrategias de adaptación y reestructuración en la dinámica familiar. La recuperación o adquisición de roles ocupacionales es un camino importante para las intervenciones con esta población.

\section{PALABRAS CLAVE}

acontecimientos que cambian la vida, responsabilidad parental, cuidadores, niños con discapacidad, Terapia Ocupacional

\begin{abstract}
The birth of a child with a disability transforms the daily life of a family, changing the occupational roles performed. The study aimed to identify possible changes in the occupational roles of parents and caregivers after the birth of a child with a disability. The approach was quantitative and qualitative. Data collection took place using the Role Checklist and a semi-structured interview. Descriptive statistics and content analysis were used for the analyses. Ten parents and caregivers of students from a School and Association of Parents and Friends of the Exceptional in the central region of Rio Grande do Sul, Brazil, participated in the study. The birth of a child with a disability may influence the performance of occupational roles, highlighting a $70 \%$ and $60 \%$ decrease in the roles of student and worker, respectively. All participants considered these to be very important in their daily lives. Over time, families have established adaptation and localization strategies in the family dynamics. Rescuing occupational roles or acquiring new ones is an important path for intervention with this population.
\end{abstract}

\section{KEY WORDS}

life changing events, parenting, caregivers, disabled children, Occupational Therapy 


\section{Introdução}

Desde o início do período gestacional, os familiares constroem um somatório de expectativas, sonhos e desejos em relação à criança. No entanto, quando nasce uma criança com deficiência a família enfrenta uma nova realidade, podendo acarretar luto pelo bebê idealizado (Santos et al., 2007). De acordo com os mesmos autores, algumas expectativas, sonhos e desejos se perdem e o impacto do nascimento de uma criança com deficiência é indefinível, pois cada família terá um enfrentamento diferente diante da nova realidade. Em muitos casos, o impacto causado pela notícia de um filho com deficiência provoca modificações na rotina, no ambiente, no contexto social e financeiro, bem como alterações relacionadas aos papéis ocupacionais. Para Hilman \& Chapparo (1995), os papéis ocupacionais se referem aos padrões de trabalho, lazer, descanso associados à cultura e aos modelos sociais de cada contexto.

Tanto a Terapia Ocupacional, quanto a Ciência Ocupacional, compreendem os sujeitos como seres ocupacionais. Através disso, buscam analisar como cada um deles percebe as suas ocupações, e como estas influenciam no desenvolvimento, na adaptação, na saúde e na qualidade de vida (Cruz \& Emmel, 2013). Entende-se que os papéis ocupacionais influenciam diretamente o dia a dia e que, no decorrer da vida, podem se modificar e sofrer rupturas. Os estudos de Barrozo et al. (2015), Behar (2018) e Polezi (2021) apontam que, após o nascimento de crianças com deficiência, os papéis ocupacionais sofrem alterações significativas, principalmente quanto ao papel de trabalhador e estudante.

Deste modo, o objetivo do presente estudo foi identificar e compreender se, a partir do nascimento de uma criança com deficiência, ocorreram mudanças nos papéis ocupacionais de mães, pais e cuidadores de alunos matriculados na Associação de Pais e Amigos dos Excepcionais, bem como apresentar como estas mudanças influenciaram no cotidiano, na saúde e na qualidade de vida dessa população. A contribuição deste estudo convoca a uma reflexão acerca da sobrecarga de mães, pais ou cuidadores diante do nascimento de uma criança com deficiência, mais especificamente, quanto à importância e ao cuidado que profissionais de saúde, em especial terapeutas ocupacionais, devem ter diante do perfil ocupacional destes sujeitos. Nesse sentido, é necessário analisar o cotidiano, os desejos, as expectativas, os sonhos desses pais, mães ou cuidadores, levando em consideração que houve uma ruptura dos ideais de vida antes desejados, em virtude dos cuidados especiais que a dinâmica familiar agora apresenta. Abdicar das atividades remuneradas, das relações sociais, entre outras atividades relevantes no cotidiano de mães, pais ou cuidadores, impacta demasiadamente a qualidade de vida e os níveis de estresse. Dessa forma, acredita-se que o estudo aponta uma demanda necessária, que se caracteriza pela análise ocupacional desses sujeitos e por um olhar sensível às possibilidades de retomada de alguns papéis ocupacionais a partir da reorganização das rotinas. 


\section{Metodologia}

Trata-se de um estudo com uma abordagem qualitativa e quantitativa, visando proporcionar a integração e a discussão conjunta, indo além das limitações de uma única abordagem (Creswell, 2010). Assim, os dados quantitativos foram coletados a partir do instrumento denominado Lista de Identificação dos Papéis Ocupacionais (LIPO), que busca entender qual a percepção do indivíduo acerca dos papéis ao longo da vida (passado, presente e futuro), bem como o grau de importância que atribuem a cada um deles. A abordagem qualitativa ocorreu por meio de um roteiro de entrevista semiestruturada, que buscou compreender, de forma mais detalhada, aspectos relacionados ao tema do estudo.

A pesquisa foi desenvolvida em uma escola especial, localizada em uma cidade da região central do Rio Grande do Sul, Brasil. Foram considerados como critérios de inclusão para o estudo mães, pais e cuidadores de crianças e adolescentes, regularmente matriculados na escola, que possuíam a idade mínima de dois e máxima de quinze anos. A amostra foi por conveniência.

A coleta de dados se deu no período de dezembro de 2020 a janeiro de 2021. Os pais, as mães e os cuidadores, que atenderam ao critério de inclusão, foram contatados e informados sobre objetivo do estudo, e assim, de acordo com a disponibilidade e a aceitação de cada um dos participantes, a coleta foi agendada individualmente. Em decorrência do agravamento da pandemia de COVID-19, a pesquisa teve um número limitado de participantes, sendo ao todo des pessoas.
A coleta de dados consistiu primeiramente na aplicação da Lista de Identificação de Papéis Ocupacionais, sendo esta uma autoavaliação baseada no Modelo da Ocupação Humana, desenvolvido primeiramente por Oakley, Kielhofner, Barris e Reichler em 1986, sendo traduzido para português e validado por Júnia Cordeiro por meio da sua dissertação de mestrado (Cordeiro, 2005; Cordeiro et al., 2007).

O instrumento foi dividido em duas partes, em que a primeira avaliou os dez principais papéis ocupacionais como: estudante, trabalhador, voluntário, cuidador, serviço doméstico, amigo, membro da família, participante em organizações, religioso, passatempo/amador e a alternativa "outros", caso o indivíduo não contemplasse os papéis existentes. Todos os papéis foram avaliados também de acordo com o tempo: passado (considerado anterior ao nascimento do filho(a) com deficiência), presente (atual) e futuro (que desejasse realizar posteriormente). Na segunda parte, os dez papéis ocupacionais foram analisados de acordo com sua importância (Cordeiro, 2005). Os dados quantitativos foram analisados estatisticamente através do programa Microsoft Excel (versão 16.0) e foram calculados em forma de frequências absoluta e relativa com valores inseridos, além disso foram apresentados por meio de tabelas e gráficos.

Realizou-se também uma entrevista semiestruturada com perguntas abertas elaboradas pela primeira autora. Esta, procurou estimular o depoimento livre das pessoas participantes, desenvolvendo perguntas sobre as possíveis mudanças que ocorreram no cotidiano após a chegada do filho com deficiência, bem como os desafios e as per- 
cepções. O instrumento e as entrevistas foram realizados concomitantemente e tiveram duração média de 30 minutos.

Os dados qualitativos foram apreciados com base na análise de conteúdo proposta por Bardin (2011), que consiste em uma análise sistemática e em etapas. Após a realização das entrevistas, os dados foram transcritos, analisados e discutidos entre as autoras deste estudo. Foram identificados, nos excertos das pessoas participantes, conceitos significativos de acordo com o objetivo do estudo. Desse modo, os dados foram codificados de acordo com a similaridade, gerando pré-categorias e, posteriormente, após nova análise, foram criadas categorias. Assim, duas categorias foram destacadas e denominadas como: Aprendendo a compreender a deficiência: do luto a aceitação; A importância dos papéis ocupacionais: rupturas e descobertas.

\section{Aspectos éticos}

Para garantir a confidencialidade e a ética, utilizou-se a codificação $F\left(n^{\circ}\right)$, a fim de buscar, primeiramente, convergências entre as pessoas participantes, portanto a letra $F$ evidenciada é referente à inicial da palavra "Familiar", pois todas se enquadram nesse perfil. Os respectivos números, de 1 a 10, foram estabelecidos de acordo com a ordem de realização das entrevistas. Em um primeiro momento, as pessoas participantes foram informadas sobre o uso de gravadores e o sigilo das informações, assim como ocorreu a leitura do Termo de Consentimento Livre Esclarecido (TCLE), reforçando a cada participante seus direitos. O estudo foi aprovado pelo Comitê de Ética e Pesquisa da Uni- versidade Federal de Santa Maria, sob parecer $n^{\circ} 4.263 .794$, homologado em 08 de setembro de 2020 .

\section{Resultados e discussão}

Participaram do estudo dez pessoas, das quais a maioria eram do sexo feminino $(n=9 ; 90 \%)$, não aposentado (a) $(n=9$; $90 \%$ ). A média de idade foi de 41,8 , variando de 26 a 65 anos, dos quais, $(n=7$; $70 \%)$ eram casadas e $(n=3 ; 30 \%)$ solteiras. Dentre os participantes, $80 \%$ eram mães, $10 \%$ pais e $10 \%$ cuidadores.

Na figura 1, são apresentados os papéis ocupacionais obtidos por meio da Lista de Identificação dos Papéis Ocupacionais e como são desempenhados segundo os tempos passado, presente e futuro. A categoria outros foi excluída do gráfico, pois não apresentou demanda nas entrevistas.

Os dez papéis ocupacionais listados foram analisados de acordo com os critérios adotados e descritos na metodologia. Destaca-se que o papel de estudante foi citado por $70 \%$ das pessoas participantes como um papel desempenhado no passado, e para $30 \%$, além de já terem exercido esse papel no passado, há o desejo de retomá-lo no futuro.

No papel de trabalhador, $40 \%$ das pessoas participantes realizam este papel no presente, $58 \%$ desempenharam no passado e pretendem recuperá-lo no futuro. Ainda, apenas 10\% nunca foram trabalhadoras e não desejam ser no futuro.

O papel de cuidador obteve uma grande percentagem entre as pessoas participantes, pois trata-se de um papel 
Figura 1. Desempenho nos papéis ocupacionais entre participantes do estudo

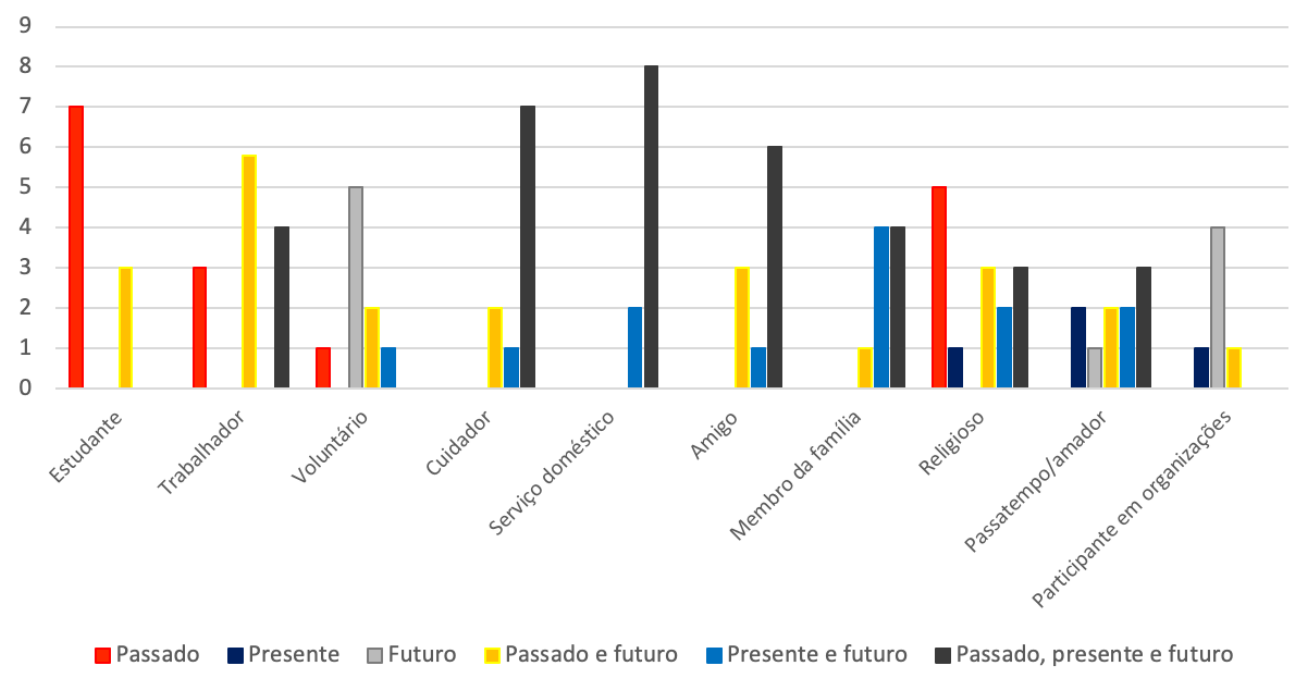

Fonte: elaboração própria.

que realizaram no passado, realizam no presente e pretendem realizar no futuro (70\%). São poucas as que não desempenham este papel no presente, apenas $10 \%$ não haviam desempenhado este papel no passado, mas realizam no presente e pretendem realizar no futuro.

Referente ao papel ocupacional de serviço doméstico, a maioria $(80 \%)$ das pessoas participantes do estudo respondeu que desempenhou no passado, desempenha no presente e pretende prosseguir no futuro.

Ainda, no papel de amigo, 60\% das pessoas entrevistadas realizam este papel no presente, realizaram no passado e têm o desejo de continuar no futuro. Ademais, 30\% responderam que no presente não realizam, mas que já realizaram no passado e pretendem retomá-lo no futuro.

Em relação ao papel ocupacional de membro de família, apenas $11,2 \%$ das pessoas entrevistadas relataram que não realizaram este papel no passado, mas realizam no presente e pretendem continuar no futuro. Uma percentagem de $44,45 \%$ relatou desempenhar no passado, desempenhar no presente e pretender desempenhar no futuro. E 44,45\% realizam no presente e têm o desejo de continuar no futuro.

Ao observar individualmente os resultados, é notável que todos os papéis ocupacionais apresentaram diminuição nas porcentagens relacionando o passado e o presente. Este dado indica que, de alguma maneira, a rotina dessas pessoas sofreu impactos diante dos papéis desempenhados. Dentre estes, os que mais sinalizaram quedas foram o de trabalhador e o de estudante, sendo os mesmos assinalados pelas entrevistadas com maior desejo de retomada ou continuidade no futuro. Esse indicativo tem relação com o nascimento dos filhos e as transformações advindas da nova realidade vivenciada. 
Na tabela 1, apresentam-se os dados referentes à segunda parte da Lista de Identificação dos Papéis Ocupacionais, que avalia o grau de importância atribuído a cada papel.

Os dados referentes à tabela 2 demonstram que todas as pessoas participantes dão maior importância aos papéis de cuidador e de membro de família. Os papéis de estudante, trabalhador, volun- tário, cuidador, serviço doméstico, amigo, membro da família e passatempo/ amador também aparecem com o grau de muita importância para a maioria das entrevistadas. Observa-se também que consideraram o papel de participante em organizações com alguma importância. Quanto ao papel atribuído à religião, os resultados indicam que $50 \%$ o consideram muito importante e $50 \%$ atribuem alguma importância.

Tabela 1. Importância dos papéis ocupacionais para participantes do estudo

\begin{tabular}{|l|c|c|c|}
\hline Papéis ocupacionais & $\begin{array}{c}\text { Nenhuma } \\
\text { importância } \\
\mathbf{n}(\%)\end{array}$ & $\begin{array}{c}\text { Alguma } \\
\text { importância } \\
\mathbf{n}(\%)\end{array}$ & $\begin{array}{c}\text { Muita } \\
\text { importância } \\
\mathbf{n}(\%)\end{array}$ \\
\hline Estudante & 0 & $4(40)$ & $6(60)$ \\
\hline Trabalhador & 0 & $1(10)$ & $9(90)$ \\
\hline Voluntário & $1(10)$ & $3(30)$ & $6(60)$ \\
\hline Cuidador & 0 & 0 & $10(100)$ \\
\hline Serviço doméstico & 0 & $3(30)$ & $7(70)$ \\
\hline Amigo & 0 & $1(10)$ & $9(90)$ \\
\hline Membro da família & 0 & 0 & $10(100)$ \\
\hline Religioso & 0 & $5(50)$ & $5(50)$ \\
\hline Passatempo/amador & 0 & $1(10)$ & $9(90)$ \\
\hline Participante em organizações & $3(33,35)$ & $4(44,45)$ & $2(22,2)$ \\
\hline
\end{tabular}

n: frequência absoluta.

Fonte: elaboração própria. 


\section{Aprendendo a compreender a deficiência: do luto a aceitação}

O nascimento de um filho é um dos momentos mais importantes e marcantes na vida da família. Segundo Iaconelli (2013), o bebê idealizado constituiu-se de uma imaginação interna de cada sujeito e do discurso social que o rodeia. Além disso, a chegada de um bebê acarreta mudanças significativas quanto aos hábitos, às rotinas, aos valores, às crenças, bem como ao ambiente. Diante disso, entende-se que as pessoas participantes tenham, de alguma forma, alterado sua rotina após o nascimento da criança, envolvendo, portanto, mudanças de papéis ocupacionais na maneira de organização das atividades e das ocupações dos membros da família. São alterações quanto aos valores e às crenças que, com a chegada de um bebê, muitas vezes passam a ser repensados. Além disso, destacam-se mudanças nas atividades de lazer antes desempenhadas. Observa-se que, as pessoas participantes, por terem uma criança com deficiência, relatam mudanças significativas na forma como percebem a vida de uma maneira geral, demonstrando maior empatia com o próximo. De las Heras (2015) destaca que os contextos são parte da ocupação, visto que, a partir dos acontecimentos vivenciados socialmente e culturalmente, associados aos fatores pessoais, pode-se compreender a participação de cada sujeito diante das atividades de rotina. Para Barrozo et al. (2015), ocorrem diversas mudanças na vida pessoal e cotidiana dos pais e dos cuidadores, relacionadas ao nascimento e ao cuidado de pessoas com deficiência, sendo um exemplo a compreensão e o comportamento social de cada família. Esse dado se confirma no relato a seguir:
Ser mãe, para mim, foi tipo um resgate, pois quando tu é mãe, e acho que principalmente mãe de uma criança com deficiência, tu sente muita coisa, sentimento que nunca havia sentido antes. No início, aceitar a deficiência não foi fácil, mas depois que compreendi, eu aprendi muita coisa também e aprendo até hoje. (F9)

Com base nesse depoimento, pode-se compreender que esse momento é permeado por diversos sentimentos e emoções, passando primeiramente pelo sofrimento e pela incompreensão da situação vivida, em seguida, vivenciando o luto pela perda do filho idealizado e, posteriormente, a aceitação da nova realidade. Ainda assim, os pais e a rede familiar compreendem como um processo, que exige a busca de alternativas para a adaptação ao novo contexto de vida.

Foi uma grande mudança, desde o nascimento, até o diagnóstico dele, mas sempre busquei o melhor. Eu não sabia muito bem como lidar, isso me afetou muito, ficava com medo. (F6)

As mudanças relacionadas aos papéis ocupacionais não se referem apenas às rupturas, mas também à aquisição de novos papéis, como o de cuidador (Barrozo et al., 2015). De acordo com os dados apresentados na Lista de Papéis Ocupacionais, observou-se que os papéis ocupacionais de cuidador e membro de família mantiveram-se com alta percentagem de participação no decorrer do tempo.

Eu sou cuidadora, todos os dias, não tem hora, sou eu quem cuido, ele precisa de muitos cuidados e cuidar dele é o que mais demanda do meu 
tempo. É praticamente vinte e quatro horas por dia, pois tem que estar sempre de olho, e eu sou a única que fica somente em casa, não estou trabalhando, então é tudo comigo, cuidar dele, da casa... (F4)

Dados similares a esses foram encontrados na pesquisa de Parreira et al. (2013), em que o papel de membro de família apresentou grande importância para a vida cotidiana dos sujeitos entrevistados, sendo considerado um elemento de apoio social, que favorece o empoderamento e os auxilia no enfrentamento da nova realidade. Ainda, de acordo com os dados obtidos nessa pesquisa, o papel de passatempo/amador diminuiu em relação ao passado, tendo em vista que muitos participantes relataram não possuírem tempo para realizar atividades de lazer, porém pretendem recuperá-la no futuro.

No início, eu abri mão de quase tudo na minha vida, meu trabalho, minha vida social, meu lazer... Agora estou, aos poucos, planejando recuperar. Por exemplo, mês que vem eu vou começar a ir na academia, que era meu passatempo, era onde eu me conectava comigo mesma, acredito que isso já é um avanço. (F9)

O papel de passatempo/amador foi considerado por $90 \%$ das pessoas participantes como de muita importância, destacando o desejo de retomar/iniciar esse papel no futuro. Envolver-se em ocupações e papéis que ofereçam lazer pode ser uma estratégia de enfrentamento, assim como é importante para a qualidade de vida dos sujeitos. Para o Modelo da Ocupação Humana, quando existe a possibilidade de escolha e interpretação do que se faz, denomi- na-se volição. A volição consiste em pensamentos e sentimentos que geram prazer, valorização, fazendo com que as pessoas se sintam competentes (Forsyth \& Kielhofner, 2003). Nesse sentido, destaca-se que as pessoas participantes do estudo demonstram falta de motivação, desejo ou volição no momento de vida atual, porém, com uma expectativa em retomar experiências e sentimentos que lhe causem prazer.

O Modelo da Ocupação Humana ressalta constructos fundamentais, como a motivação, a habituação, os valores, a causação pessoal, bem como compreende os papéis inseridos nesse contexto, em que os hábitos, costumes e interesses se interligam. Dessa forma, são construídos padrões de comportamento, em que ações são desempenhadas no meio social e cultural de acordo com o que é esperado diante do papel ocupacional (Forsyth \& Kielhofner, 2013). Sendo assim, o estudo ressalta que, a partir da nova realidade enfrentada pelos pais, houve a aquisição de novos hábitos, valores, crenças e, consequentemente, papéis ocupacionais. De modo geral, o presente estudo identificou mudanças nos papéis ocupacionais dos sujeitos entrevistados relacionadas com o nascimento do filho, principalmente no que diz respeito à dinâmica familiar, aquisição de novos papéis, como o de cuidador; abdicação de papéis, como estudante e trabalhador; bem como diminuição das atividades de lazer e do papel de amigo, alertando, portanto, para a necessidade de cuidado e atenção diante da saúde emocional e física destes sujeitos que, além da sobrecarga gerada pela nova realidade, precisaram abandonar, temporariamente ou definitivamente, ocupações importantes para qualidade de vida e autoestima (ou autoeficácia). 


\section{A importância dos papéis ocupacionais: rupturas e descobertas}

As ocupações são compreendidas como um modo ativo do sujeito intervir no mundo e, assim, ativamente, estar consigo e com os outros (Hocking, 2011). Além disso, as ocupações são influenciadas pelo tempo, lugar e pelas condições sociais e econômicas de cada sujeito. Acredita-se que os papéis ocupacionais estejam diretamente ligados às ocupações.

De acordo com os dados dessa pesquisa, o papel de trabalhador se destaca como um dos mais comprometidos, apresentando uma queda significativa no presente, visto que apenas $40 \%$ das pessoas participantes mantiveram o papel de trabalhador após o nascimento do filho, e 58\% têm o desejo de retomar esse papel, sendo considerado por $90 \%$ dos entrevistados como muito importante. Conforme De las Heras (2015), existe uma relação muito estreita entre os processos de participação e a mudança ocupacional, em que os componentes ocupacionais pessoais e do ambiente contribuem para a participação nas ocupações. Este estudo demonstra que o papel do trabalhador sofreu mudanças após o nascimento de um bebê com deficiência, pois, a partir desse acontecimento, as demandas do ambiente em que essas famílias vivem precisaram ser repensadas para que houvesse um cuidado integral.

Assim, outro processo ocupacional relevante passa a ser reconhecido - que é o da emergência, ou seja, a participação espontânea em ocupações, que, no caso deste estudo, está caracterizada como o papel de cuidador. Esse dado indica que os acontecimentos gerados a partir de uma demanda social, de saúde ou familiar, podem interferir nos papéis desempenhados. Por conta da nova realidade, muitos pais, principalmente a figura materna, que compõe 90\% dos entrevistados desta pesquisa, veem-se impossibilitados de conciliar a rotina de cuidados com o emprego e acabam por abdicar deste, para se dedicar integralmente aos filhos, como no relato a seguir:

O trabalho foi uma das principais coisas que precisei abrir mão e me faz muita falta, não somente pelo lado financeiro, mas também porque eu gostava de ter meu dinheiro, gostava do meu trabalho e colegas. (F7)

Para Cruz \& Emmel (2013), a influência do gênero levanta uma questão importante sobre os papéis ocupacionais, principalmente em relação ao papel de cuidador, que indica diferenças entre homens e mulheres, podendo estar relacionada às questões culturais e sociais. Além da renúncia ao papel de trabalhador, os resultados obtidos indicam um declínio nos papéis de amigos e estudantes, que deixaram de ser exercidos quando comparados ao passado, mas obtêm um índice significativo de pretensão para o futuro. Cabe destacar que a faixa etária das pessoas participantes variou entre 26 e 65 anos, sendo considerada uma fase ainda produtiva da maior parte da população. Isso se reflete nos $60 \%$ que destacam o papel de estudante com muita importância.

Estudar, trabalhar e se envolver em atividades sociais são ocupações que acarretam reconhecimento, valorização, sentimento de autoeficácia e autoestima, influenciando, portanto, na saúde 
mental e emocional. Guerra et al. (2015) ressaltam que os cuidados aos filhos com deficiência em tempo integral podem gerar um distanciamento da identidade de uma mulher que assume exclusivamente o papel de mãe para que o filho tenha um cuidado e um desenvolvimento melhor.

Com a aquisição do papel materno/ paterno, surgem novas demandas na rotina dos indivíduos, sendo assim, quando questionados sobre as mudanças nos papéis ocupacionais, todas as pessoas participantes relataram que têm relação com a participação social. O papel de amigo foi mencionado pela maioria das pessoas. $90 \%$ relatam ser um papel muito importante. Os estudos de Estanieski \& Guarany (2015) e Polezi (2021) demonstram que o papel de amigo deixou de ser exercido devido à demanda de cuidados especiais pelos filhos, destacando que não existe um tempo na rotina familiar para a realização de atividades sociais. Os cuidados requerem mais assistência, supervisão e, portanto, mais envolvimento nestas ocupações por parte dos cuidadores e, consequentemente, estes abandonam atividades prazerosas, como estar entre amigos, viajar, participar de festas, entre outros momentos de lazer e de interação social.

Eu senti muita falta da minha vida social, eu tinha muitos amigos, eu saía, eu vivia mais, eu dançava, eu ia a festas, frequentava clubes, e quando o R. nasceu, eu não consegui fazer mais nada disso e eu senti muita falta. Ali eu percebi que era muito importante para mim minha vida social, até hoje, depois de nove anos, me faz muita falta. (F7)

Os discursos ressaltam que, com a nova rotina, os sujeitos priorizam mo- mentos com seus filhos, diminuindo a frequência das atividades de lazer e uma maior seletividade quanto à escolha aos lugares que os levam, afetando a manutenção de papéis que envolvem as relações sociais. A rotina de qualquer mãe, pai ou cuidador de crianças (sejam elas com deficiência ou não) acarreta transformações. Contudo, para aqueles que têm crianças com deficiência, a rotina de cuidados se torna mais intensa, além da dificuldade de frequentar espaços acessíveis aos seus filhos ou ainda uma escola infantil que os receba da maneira como merecem e necessitam.

Minha vida social mudou, eu saía, vi-
sitava as pessoas, as pessoas me visi-
tavam, e desde que o G. chegou, eu
precisei ajustar tudo à rotina dele, eu
precisei entender, respeitar e ajustar de
acordo com o que ele se sente melhor.
Ele não consegue ficar muito tempo
longe de mim, o que dificulta a volta
das minhas atividades de lazer, mas aos
poucos vamos conseguindo. (F10)

Segundo Barbosa \& Fernandes (2009), o círculo de vida social da família com uma criança com deficiência geralmente é suprimido de maneira que os pais, mães e cuidadores, por muitas vezes, abdiquem de momentos de lazer, de participação social e autocuidado para atender as demandas de cuidado ao filho. Das pessoas entrevistadas, $100 \%$ consideraram o papel de cuidador como muito importante, sendo que $70 \%$ já realizaram esse papel no passado, realizam no presente e pretendem realizar no futuro. Ainda, oito dos dez sujeitos entrevistados relataram que, além de tornarem-se mães/pais, realizam a função de cuidador principal. 
Nesse sentido, constata-se que as mudanças na rotina, bem como nas relações interpessoais entre os membros da família, são inevitáveis. Entretanto, conforme os dados deste estudo, quando mães, pais e cuidadores abdicam de suas atividades de trabalho, relações sociais, lazer, existe um evidente desconforto e desejo em retomá-los, visto que são papéis que fazem falta no cotidiano. É imprescindível que não haja naturalização dessas rupturas, uma vez que, ao tornar-se cuidador de uma pessoa com deficiência, existe uma sobrecarga e uma diminuição de atividades que estimulam o bem-estar e lazer, o que pode ocasionar prejuízos na qualidade de vida e adoecimento. Para o Modelo da Ocupação Humana, sempre existe uma inter-relação no que tange a como as pessoas se sentem estimuladas e motivadas para desempenhar suas atividades ou ocupações (volição), e como estão realizando essa ação ao longo do tempo repetidamente (habituação). A cada momento em que as ocupações são realizadas novamente, elas podem se alterar quanto à forma como são percebidas as capacidades de desempenho. Essas situações são desenvolvidas em um contexto físico, cultural, financeiro, facilitando ou dificultando o engajamento ocupacional (Taylor, 2017).

Eu tive depressão. No início foi muito difícil, mas agora eu estou bem. Eu comecei a fazer tipo uma caixinha organizadora na minha vida, e comecei a separar, me dei conta que eu sou mãe da E., do G., sou esposa, sou filha e sou mulher também, então eu precisava também me colocar como prioridade. (F5)
Apesar da sobrecarga de cuidados, as participantes do estudo demonstraram modos de enfrentamento, se adaptando ao processo de ter uma pessoa com deficiência na família, e considerando tal processo um período de aprendizagem.

Me tornar mãe do R. me fortaleceu, aprendi a ser uma mãe melhor, tanto para meu filho mais novo quanto para o meu filho mais velho, aprendi a ter mais empatia, passei a olhar as pessoas e o mundo de uma forma diferente. (F4)

Destaca-se que, quanto às relações sociais, cinco participantes relataram a troca de experiências de vida com outros pais e cuidadores como algo relevante, sendo considerada uma estratégia que ajudou na adaptação de situações vivenciadas no cotidiano. Esse contato, de certa forma, gera tranquilidade, pois os indivíduos percebem que outros também vivenciam experiências semelhantes a sua.

O nascimento do D. foi uma aprendizagem, uma nova forma de amar. $A$ melhor coisa que aconteceu na minha vida... Tu aprende a amar também o filho do outro, eu conheci pessoas incriveis, que pude compartilhar experiências e que me ajudou a perceber que tudo é aprendizado. (F9)

Desta maneira, percebe-se a importância do estabelecimento de uma rede mínima de suporte social para que o cuidador possa realizar, além das atividades destinadas ao cuidado, atividades e estratégias para que o seu autocuidado, entretenimento e lazer sejam mantidos.

A pesquisa ainda identificou, através da Lista de papéis ocupacionais e da en- 
trevista, dados que destacam inicialmente a busca dos familiares pela compreensão acerca da deficiência, considerando esse um processo de aprendizagem.

O que mudou bastante para mim, foi a questão de enxergar as pessoas com deficiência, antes me lembro de chamar as pessoas de "doentinhas", e achar que tudo bem. Hoje eu percebi que estava errado, aprendi muito e ainda estou aprendendo, hoje sei que é uma deficiência, que faz parte dela... A sociedade muitas vezes trata as pessoas com deficiência de outra maneira, então eu mudei totalmente meus pensamentos. Hoje em dia, busco sempre estar informado e passar informação a outras pessoas. (F2)

Ainda, identificaram-se semelhanças entre as falas das pessoas participantes, assim como expressões que indicam realizações, desejos e mudanças, ou seja, expectativas em relação ao futuro.

Ela precisa da nossa ajuda com certeza, mas a gente precisa sempre investir nela, fazê-la ficar mais independente ainda, então eu nunca vou deixar de fazer nada em função das limitações dela, e também vou sempre incentivar ela a tentar, mesmo com as dificuldades. (F1)

Percebe-se então que as fases de negação e luto, identificadas inicialmente, cedem lugar para uma fase de aceitação e de reorganização. A percepção de possibilidades mantém a esperança nos pais, mães e cuidadores, que demonstram (a partir de suas falas) expectativas e idealizações. Segundo Ferreira et al. (2012), a resiliência é uma ferramenta de transformação humana, pois dá o poder aos indivíduos de se transformarem e de transformar a realidade em que vivem, além de oferecer condição de encontrar, em si mesmo e ao redor de si, todos os elementos que lhe permitem criar essa capacidade de superação.

A gente aprende muito com as crianças com deficiência. Hoje eu me tornei um ser humano melhor, eu aprendi a valorizar muitas coisas e valorizar as pessoas, hoje eu dou muito mais valor a tudo, devido aos ensinamentos que meu filho me trouxe. (F6)

Diante do exposto, pode-se observar o quanto o nascimento de uma criança com deficiência representa um universo de desafios e mudanças no cotidiano da família. Sendo assim, destaca-se a importância do terapeuta ocupacional, visto ser o profissional apto a analisar o perfil e a identidade ocupacional, o contexto de vida e a relevância de cada ocupação.

Dessa forma, o profissional poderá atuar na reorganização do cotidiano dos pais, mães e cuidadores, resgatando a realização de atividades significativas abdicadas, advindas do cuidado ao filho, além da organização da rotina, escuta e acolhimento. Para Polatajko et al. (2013), deve existir equilíbrio entre as ocupações e as demandas internas. Assim, destaca-se que, quando existe um desequilíbrio destas, pode haver impacto na rotina, gerando desarmonia, problemas de saúde física e emocional, bem como disfunção ocupacional. Identificou-se que as alterações na rotina se caracterizam por um processo de adaptação, desenvolvido conforme a capacidade de resiliência de cada rede familiar. 
Por fim, destaca-se que apesar dos problemas que perpassam a questão da deficiência na família, os familiares reagiram às adversidades, adaptaram-se às alterações e encararam essa realidade com persistência, solidariedade, criatividade e, principalmente, amor.

\section{Considerações finais}

Com base neste estudo, foi possível observar que, após o nascimento da criança com deficiência, as famílias entrevistadas apresentaram alterações no desempenho de seus papéis ocupacionais. Dentre esses papéis, destacam-se os de trabalhador, amigo e estudante. Além disso, nota-se que os familiares tiveram seu dia a dia, suas tarefas e seus papéis modificados por um tempo que varia de acordo com a realidade de cada núcleo familiar, devido aos cuidados necessários à criança, o que acarretou queda de atividades de autocuidado, lazer, alterações quanto à volição, à habituação, aos valores, às crenças e aos hábitos. Diante da identificação de que houve uma diminuição na participação de papéis desempenhados para o tempo presente, considera-se a necessidade de readaptação desses sujeitos e do incentivo à participação em papéis ocupacionais - que são considerados importantes no cotidiano dos entrevistados.

Os papéis ocupacionais de cuidador e de serviços domésticos mantiveram-se durante todos os períodos, sendo citados como os principais papéis realizados no dia a dia. As pessoas entrevistadas desenvolveram estratégias (que não foram contempladas neste estudo), para se adaptarem às mudanças no seu cotidiano, sendo necessária a reestruturação familiar, redefinição de papéis e criação de novas possibilidades.

Como desafio encontrado para elaboração deste estudo, revela-se a escassez de produções da Terapia Ocupacional voltadas para a temática, sendo necessário o desenvolvimento de mais estudos acerca desse tema. Além disso, o número de participantes foi limitado, devido ao enfrentamento da pandemia de COVID-19, que dificultou o acesso e o contato com as famílias.

Por fim, se faz necessário que seja ampliada a percepção dos profissionais da saúde acerca das alterações encontradas no âmbito familiar após o nascimento de uma criança com deficiência, possibilitando a compreensão da realidade que os cerca. Acredita-se que este estudo possa contribuir com as famílias de crianças com deficiência, assim como poderá subsidiar futuras pesquisas de intervenção do terapeuta ocupacional, buscando ampliar o cotidiano, além de recuperar o desempenho ocupacional e os papéis ocupacionais, estimulando o resgate de cada indivíduo. 


\section{Referencias}

Barbosa, M. R. P. \& Fernandes, F. D. M. (2009). Qualidade de vida dos cuidadores de crianças com transtorno do espectro autístico. Revista da Sociedade Brasileira de Fonoaudiologia, 14(4), 482-486. https://doi.org/10.1590/S1516$\underline{80342009000400009}$

Bardin, L. (2011). Análise de conteúdo. Edições 70.

Barrozo, B. M., Nobre, M. I. R. \& Montilha, R. de C. I. (2015). As alterações nos papéis ocupacionais de cuidadores de pessoas com deficiência visual. Revista de Terapia Ocupacional da Universidade de São Paulo, 26(3), 409-417. https://doi.org/10.11606/issn.22386149.v26i3p409-417

Behar, R.C.R. (2018). A maternidade e seu impacto nos papéis ocupacionais primíparas [Trabalho final de graduação, Universidade Federal da Paraíba]. Repositório UFPB. https://repositorio.ufpb.br/ jspui/bitstream/123456789/12177/1/ RCRB29062018.pdf

Cordeiro, J. R. (2005). Validação da lista de identificação de papéis ocupacionais em pacientes portadores de doença pulmonar obstrutiva crônica (DPOC) no Brasil [Tese de mestrado, Universidade Federal de São Paulo]. Repositório Unifesp. https://repositorio.unifesp. br/handle/11600/20599

Cordeiro, J. R., Camelier, A., Oakley, F. \& Jardim, J. R. (2007). Cross-cultural reproducibility of the Brazilian Portuguese version of the Role Checklist for chronic obstructive pulmonary disease patients. American Journal of Occupational Therapy, 61(1), 33-40. https://doi.org/10.5014/ajot.61.1.33
Creswell, J. W. (2010). Uma estrutura para projeto. In J. W. Creswell, Projeto de Pesquisa: métodos qualitativos, quantitativo e misto (pp.21-30). Artmed/ Bookman.

Cruz, D. M. C. \& Emmel, M. L.G. (2013). Associação entre papéis ocupacionais, independência, tecnologia assistiva e poder aquisitivo em sujeitos com deficiência física. Revista Latino-Americana de Enfermagem, 21(2), 484-491. https://doi. org/10.1590/S0104-11692013000200003

De Las Heras, C. G. (2015). Modelo de ocupación humana. Síntesis.

Estanieski, I. I. \& Guarany, N. R. (2015) Qualidade de vida, estresse e desempenho. Revista de Terapia Ocupacional da Universidade de São Paulo, 26(2),194-200. https://doi.org/10.11606/issn.22386149.v26i2p194-200

Ferreira, C. L. S., Lúcia, M. O. \& Maia, E. M. C. (2012). Resiliência em idosos atendidos na Rede de Atenção Básica de Saúde em municípios do nordeste brasileiro. Revista da Escola de Enfermagem da USP, 46(2), 328-334. https://doi.org/10.1590/ $\underline{\text { S0080-62342012000200009 }}$

Forsyth, K. \& Kielhofner, G. (2003). Model of Human Occupation. In P. Kramer, A. J. Hinojos \& C. B. Royeen (eds.), Perspectives in Human Occupation: participation in life (pp. 45-86). Lippincott Williams \& Wilkins.

Forsyth, K. \& Kielhofner, G. (2013). The model of human occupation: Embracing the complexity of occupation by integrating theory into practice and practice into theory. In E.A.S. Duncan (ed.), Foundations for practice in Occu- 
pational Therapy (pp. 51-80). Churchill Livingstone.

Guerra, C. S., Dias, M. D., Filha, M. O. F., Andrade, F. B., Reichert, A. P. S. \& Araújo, V. S. (2015). Do sonho à realidade: vivência de mães de filhos com deficiência. Texto contexto em enfermagem, 24(2) 459- 466. https://doi.org/10.1590/0104$\underline{07072015000992014}$

Hillman, A. M. \& Chapparo, C.J. (1995). An investigation of occupational role performance in men over sixty years of age, following a stroke. Journal of Occupational Science, 2(3), 88-99. https://doi.org/ $\underline{10.1080 / 14427591.1995 .9686399}$

Hocking, C. (2011). Contribuição da ocupação para a saúde e o bem-estar. En M. E Neistadt \& E. B. Crepeau, Willard \& Spackman: Terapia Ocupacional 9. ed. (pp. 45-55). Médica Panamericana.

laconelli, V. (2013). Mal-estar na maternidade: do infanticídio à função materna [Tese Doutorado, Universidade Federal de São Paulo]. Digital Library USP. https://doi.org/10.11606/T.47.2013.tde07052013-102844

Parreira, M. M., Cavalcanti, A., Cunha, J. H. S. \& Cordeiro, J. J. R. (2013). Papéis ocupacionais de indivíduos em condições reumatológicas. Revista de Terapia Ocupacional da Universidade de São Paulo, 24 (2), 127-133. http://dx.doi.org/10.11606/ issn.2238-6149.v24i2p127-133

Polezi, S.C. (2021). Papéis e desempenho ocupacional de mães de crianças com deficiências [Dissertação de mestrado, Universidade Federal de São Carlos]. Repositório UFSCar. https://repositorio. ufscar.br/handle/ufscar/14473?show=full
Polatajko, H. J., Townsend, E. A. \& Craik, J. (2013). The CMOP-E and other models of occupation. In E.A. Townsend \& H. J. Polatajko (eds.), Enabling occupation II: Advancing an occupational therapy vision of health, well-being, \& justice through occupation (pp. 27-32). CAOT Publications ACE.

Santos, S. S. C., Pelzer, M. T. \& Rodrigues, M. C. T. (2007). Condições de enfrentamento dos familiares cuidadores de idosos portadores de doença de Alzheimer. Revista Brasileira de Ciências do Envelhecimento Humano, 4(2), 114-126. http:// repositorio.furg.br/handle/1/1798

Taylor, R. R. (2017). Kielhofner's Model of Human Occupation 5th. ed. Wolter Kluwer. 